2. Böyum, A.: Isolation of mononuclear cells and granulocytes from human blood. Scand. J. Clin. Lab. Invest., 21: 776 (1968).

3. Brown, G., and Greaves, M. F., Enumeration of absolute numbers of $\Upsilon$ and $B$ lymphocytes in human blood. Scand. J. Immunol., 3: 16 (1974).

4. Clausen, C. R., Munoz, J., and Bergman, R. K.: Reaginic type of antibody in mice stimulated by extracts of Bordetella pertussis. J. Immunol., 103: 768 (1969).

5. Cooper, M. D., Peterson, R. D. A., and Good, R. A.: Delineation of the thymic and bursal lymphoid systems in the chicken. Nature, 205: 143 (1965).

6. Dresser, D. W., Wortis, H. H. H., and Anderson, H. R., The effect of pertussis vaccine on the immune response of mice to sheep red blood cells. Clin. Exp. Immunol. 7: 871 (1970).

7. Ford, W. L., and Gowans, J. C.: The traffic of lymphocytes. Semin. Hematol., 6: 67 (1969).

8. Iwasa, S., Yoshikawa, T., Fukumura, K., and Kurokawa, M.: Effects of the lymphocytosis-promoting factor from Bordelella pertussis on the function and potentiality of lymphocytes. I. Effect on the ability of lymphocytes to recirculate in the body. Japan J. Med. Sci. Biol., 23: 47 (1970).

9. Jondal, M., Holm, G., and Wigzell, H.: Surface markers on human T and B lymphocytes forming nonimmune rosettes with sheep red blood cells. J. Exp. Med., 136: 205 (1972).

10. Kalpaktsoglou, P. K., Yunis, E. J., and Good R. A.: Changes produced by pertussis antigen on the blood cells and lympho-haemopoietic tissues after early and late thymectomy of splenectomy. Clin. Exp. Immunol., 5: 91 (1969).

11. Kaplan, J., Mastrangelo, R., and Peterson, W. D., Jr.: Childhood lymphoblastic lymphoma, a cancer of thymus derived lymphocytes. Cancer Res., 34: 521 (1974).

12. Kind, L. S.: The altered reactivity of mice after inoculation with Bordetella pertussis vaccine. Bactiol. Rev., 22: 173 (1958).
13. Morse, S. I.: Studies on the lymphocytosis induced in mice by Bordetella pertussis. J. Exp. Med., 121: 49 (1964).

14. Morse, S. I., and Riester, S. K.: Studies on the leukocytosis and lymphocytosis induced by Bordetella pertussis. I. Radioautographic analysis of the circulating cells in mice undergoing pertussis-induced hyper leukocytosis. J. Exp. Med., 125: 401 (1967).

15. Morse, S. I., and Riester, S. K.: Studies on the leukocytosis and lymphocytosis induced by Bordetella pertussis. II. The effect of pertussis vaccine on the thoracic duct lymph and lymphocytes of mice. J. Exp. Med., 125: 619 (1967).

16. Morse, S. I., and Riester, S. K.: Studies on the leukocytosis and lymphocytosis induced by Bordetella pertussis. III. The distribution of transfered lymphocytes in pertussis-treated and normal mice. J. Exp. Med., 132: 663 (1970).

17. Pieroni, R. E., and Levine, L.: Adjuvant principle of pertussis vaccine in the mouse. Nature, 211: 1419 (1966)

18. Rai, K. R., Chanana, A. D., Cronkite, E. P., Joel, D. D., and Stevens, J. B. Studies on lymphocytes. III. Mechanism of lymphocytosis induced by supernatant fluids of Bordetella pertussis cultures. Blood, 38: 49 (1971).

19. Ross, F. D., Rabellino, E. M., Polley, M. J., and Grey, H. M.: Combined studies of complement receptors and surface immunoglobulin-bearing cells and sheep erythrocyte rosette-forming cells in normal and leukemic human lymphocytes. J. Clin. Invest., 52: 377 (1973)

20. Taub, R. N., Rosett, W., Odler, A., and Morse, S. I.: Distribution of labeled lymph node cells in mice during lymphocytosis induced by Bordetella pertussis. J. Exp. Med., 136: 1581 (1972).

21. This work was supported by the Kales fund.

22. Requests for reprints should be addressed to: R. Bernales, M.D., Georgetown University Medical Center, Gorman Bldg., Rm. 130, 3800 Reservoir Rd., N.W., Washington, D. C. 20007 (USA).

23. Accepted for publication June 4, 1976. uridine diphosphate glucuronyl transferase uridine diphosphate xylosyl transferase

\title{
Xylose, Glucose, and Glucuronic Acid Conjugation of Bilirubin in the Newborn Rat
}

\author{
SERGIC L. VAISMAN, KWANG-SUN LEE, AND LAWRENCE M. GARTNER ${ }^{(25)}$ \\ Division of Neonatology, Department of Pediatrics, The Rose F. Kennedy Center for Research in Mental Retardation \\ and Human Development and the Liver Research Center, Albert Einstein College of Medicine, Bronx, New York,
}

$U S A$

\section{Extract}

The development and relative contribution of hepatic bilirubin conjugation with glucuronic acid, xylose, and glucose was studied in vitro in newborn rats $1-20$ days old. In adult control rats, $75 \%$ of the conjugates formed were with glucuronic acid, whereas in 1-day-old newborns, only $50 \%$ of the conjugates were with glucuronic acid $(P<0.02)$ while xylose and glucose conjugates of bilirubin together were equal to that of glucuronic acid. By day 4 , total conjugating capacity increased to adult levels and a mature pattern of distribution. In response to phenobarbital treatment, xylose and glucose conjugation increased 4 days earlier than glucuronide conjugation and maximal induction occurred 8 days sooner for nonglucuronide conjugation than for glucuronide.

\section{Speculation}

The pattern of enzyme maturation and relative activities of the various bilirubin conjugating systems in newborn rats cannot be extrapolated to those in the human, but this study suggests that a similar study in the human or subhuman primate might demonstrate that glucose and xylose conjugation compensate, in part, for deficient glucuronide conjugation.

In mammalian species bilirubin is conjugated primarily with glucuronic acid at the site of the hepatic endoplasmic reticulum (microsomes) to form the water-soluble form of bilirubin for excretion into bile. It has long been recognized that fetal and newborn liver of all species is deficient in capacity to form the glucuronide conjugate of bilirubin because of marked reduction in bilirubin glucuronyl transferase activity $(2,13,20)$. Recent study in newborn monkeys has demonstrated that the inability of the newborn liver to form bilirubin conjugates is largely responsible for the early phase of physiologic jaundice $(7,8)$.

Other carbohydrate conjugates of bilirubin, in addition to glucuronides, are formed in all species studied thus far, as has been demonstrated in vitro $(4,5)$ and by chromatographic separation of the pigments in bile $(4,11)$. These studies have been limited to the adult age group and the formation of nonglucuronide conjugates by the fetus and newborn has never been examined. Consideration must be given to the possibility that nonglucuronide conjugates of 
bilirubin may compensate for deficient glucuronide conjugation during neonatal life.

We have previously demonstrated that 5-day-old Dornjou rats treated with phenobarbital during the first 4 days of life failed to demonstrate the expected induction of bilirubin glucuronide formation in vitro (17). The present study in the Sprague-Dawley strain of rats similarly has demonstrated no response to phenobarbital treatment during the first 4 days of life. This raised a second question as to whether drug induction of nonglucuronide conjugates by the newborn rat was either similarly unresponsive or, possibly, more responsive.

This study was undertaken to evaluate the development and relative contribution of three different bilirubin conjugating systems in the newborn rat, both in the native state and after phenobarbital stimulation. The three enzymes studied were uridine diphosphate glucuronyl transferase (UDPGT), uridine diphosphate xylosyl transferase (UDPXT), and uridine diphosphate glucosyl transferase (UDPGST) for the conjugation of bilirubin with glucuronic acid, xylose, and glucose, respectively.

\section{MATERIALS AND METHODS}

Sprague-Dawley pregnant rats were obtained from Marland Breeding Farms, Wayne, N. J. They were kept in individual breeding cages and allowed to deliver spontaneously. The newborn rats were studied on days $1,4,8,12,16$, and 20 of life. Phenobarbital from Amend Drug \& Chemical Co., Inc. was prepared in $0.1 \mathrm{~N} \mathrm{NaOH}$ and $\mathrm{pH}$ adjusted to 8.4 with $12 \mathrm{~N} \mathrm{HCl}$ and used for only $48 \mathrm{hr}$. Phenobarbital (PB) was administered subcutaneously in doses of $15 \mathrm{mg} / \mathrm{kg}$ once every $24 \mathrm{hr}$ for the 4 days immediately preceding study for the newborns killed on days $8,12,16$, and 20 . In the group studied on day $1, \mathrm{~PB}$ was administered to the pregnant mother from day 18 to 21 of pregnancy in doses of $100 \mathrm{mg} / \mathrm{kg}$.day, subcutaneously. In the group killed on day 4, PB was administered to the pregnant mother on the $21 \mathrm{st}$ day of pregnancy $(100 \mathrm{mg} / \mathrm{kg})$ and to the newborn from day $l$ to $3(15 \mathrm{mg} / \mathrm{kg})$. The control group received the same volume of $0.1 \mathrm{~N} \mathrm{NaOH}, \mathrm{pH}$ 8.4. Adult female rats weighing 260-290 g were treated either with PB at a dose of $100 \mathrm{mg} / \mathrm{kg} \cdot$ day for 3 days or received an equal volume of $0.1 \mathrm{~N} \mathrm{NaOH}, \mathrm{pH} 8.4$.

All animals were weighed daily and immediately before death. Control and PB-treated rats were exsanguinated under ether anesthesia $24 \mathrm{hr}$ after the last injection. The livers were immediately removed, washed in ice-cold $0.154 \mathrm{M} \mathrm{KCl}$, and homogenized. For the determinations on days $I$ and 4 several livers were pooled (3-13 livers for one determination). The mean for each day represents 6-12 determinations. Assays of bilirubin UDPGT, UDPXT, and UDPGST were immediately performed using whole liver homogenates, digitonin activated, with optimal concentrations of the following, obtained from Sigma Chemical Co., St. Louis, Mo.: UDP glucuronic acid (UDPGA, $6.19 \times 10^{-2} \mathrm{M}$ ), UDP xylose (UDPX, $7.46 \times 10^{-2} \mathrm{M}$ ), and UDP glucose (UDPG, $\left.6.56 \times 10^{-2} \mathrm{M}\right)$. A micromodification of the previously described method was utilized so that all volumes were reduced to one-fifth of that previously used (6).

UDPGT, UDPXT, and UDPGST activities were expressed as micrograms of bilirubin conjugated per liver per $40 \mathrm{~min}$ after correction for blank (no UDPGA, UDPX, or UDPG). Total liver protein concentration was measured according to the method of Lowry (14). Student's $t$-test was used for determination of statistically significant differences between groups at a significance level of $P<0.05$ for the two-tailed test (15).

\section{RESULTS}

\section{UDPGT, UDPXT, AND UDPGST ACTIVITIES}

In the control group, total conjugating capacity in vitro, calculated by summation of the three enzyme activities, increased from a low level (20\% of adult normal) at birth to reach adult activity by day 4 (Fig. 1). Total enzyme activity exceeded the adult level by about $30 \%$ on days 12, 16, and 20 (Fig. 1). PB administration did not produce any increase in activity in animals



Fig. 1. Uridine diphosphate glucuronyl transferase (hatched block), uridine diphosphate xylose transferase (open block), and uridine diphosphate glucosyl transferase (dotted block) activities in newborn and adult rats with and without phenobarbital treatment. Activity is expressed as micrograms of bilirubin conjugated per $\mathrm{g}$ liver per $40 \mathrm{~min}$ (mean $\pm \mathrm{SE}$ ). Numbers in parentheses indicate the number of determinations in each group. $P B$ : phenobarbital-treated group. 




Fig. 2. Analysis of the contribution of uridine diphosphate glucuronyl transferase (UDPGT), uridine diphosphate xylosyl transferase (UDPXT). and uridine diphosphate glucosyl transferase (UDPGST) in adult and newborn untreated rats. Results are expressed as the mean percentage of distribution of each group $\pm \mathrm{SE}$. *: significantly different from adult distribution. Number of determinations in each group: adult, 6; 1 day, 12; 4 days, $6 ; 8$ days, $6 ; 12$ days, $10 ; 16$ days, 12;20 days, 6 .

1 and 4 days old but on days $8,12,16$, and 20, significant increases of from 26 to $32 \%$ were seen $(P<0.01)$.

The analysis of the contribution of each of the three enzymes in the control animals is presented in Figure 2. UDPGT (glucuronic acid) activity in adult rats without PB stimulation accounted for $74.5 \%$ of total conjugating activity, whereas UDPXT (xylose) accounted for $17.6 \%$ and UDPGST (glucose) $7.9 \%$. In the first day of life UDPGT activity accounted for only $50 \%$ of total activity, a significant reduction as compared with the adult $(P<0.02)$. UDPXT increased to $28 \%$ and UDPGST to $22 \%$ of total activity. These increases were not significant, however.

By day 4, the distribution was returning toward that of the adult and by day 8 and thereafter was not significantly different from that of the adult.

The percentage of increase in conjugation with each of the three substrates after PB administration is illustrated in Figure 3. As noted previously for total conjugating activity, PB did not significantly increase the formation of any of three conjugates alone on days 1 and 4 in the newborns. On day 8, UDPXT and UDPGST activities increased by $80 \%$ and $88 \%$, respectively, in response to $\mathrm{PB}$ administration as compared with controls of the same age. This significant increase on day $8(P<0.01)$ contrasts with insignificant increase of glucuronide formation $(P>0.10)$. By day 12, the degree of UDPXT and UDPGST enhancement after $\mathrm{PB}$ as compared with controls declined, although the degree of enhancement remained significant, whereas UDPGT enhancement became significant $(P<0.01)$. Peak UDPGT activity occurred on day 16,8 days later than the peak enhancement for UDPXT and UDPGST.

\section{LIVER WEIGHT}

In the control group relative liver weight was greatest on day $I$, decreased progressively to day 8 , and increased after this time to reach adult size by day 16 (Table 1). The PB-treated group had a similar pattern of progression in relative liver size, but liver weights on days $4,8,16$, and 20 were significantly greater than controls.

\section{LIVER PROTEIN CONCENTRATION AND TOTAL LIVER PROTEIN}

In the control group liver protein concentration rose progressively from day $l$ to a maximum on day 16 (Table 1). PB administration did not produce a significant change in liver protein concentration on any day of study, but total hepatic protein relative to total body weight was increased significantly on days 8 , 16,20 , and in the adult rat.

If enzyme activities are expressed relative to body weight (micrograms of bilirubin conjugated per $100 \mathrm{~g}$ body weight per 40 min) or relative to liver protein concentration (micrograms of bilirubin conjugated per $\mathrm{mg}$ protein per $40 \mathrm{~min}$ ), the pattern and degree of response to $\mathrm{PB}$ administration is the same as when expressed per liver mass.

\section{DISCUSSION}

In the untreated newborn rat we have found a rapid increase in total bilirubin conjugating capacity in vitro from days 1 to 4 , as would be expected from previous reports. The previously reported patterns of maturation and activity of UDPGT (the only bilirubin
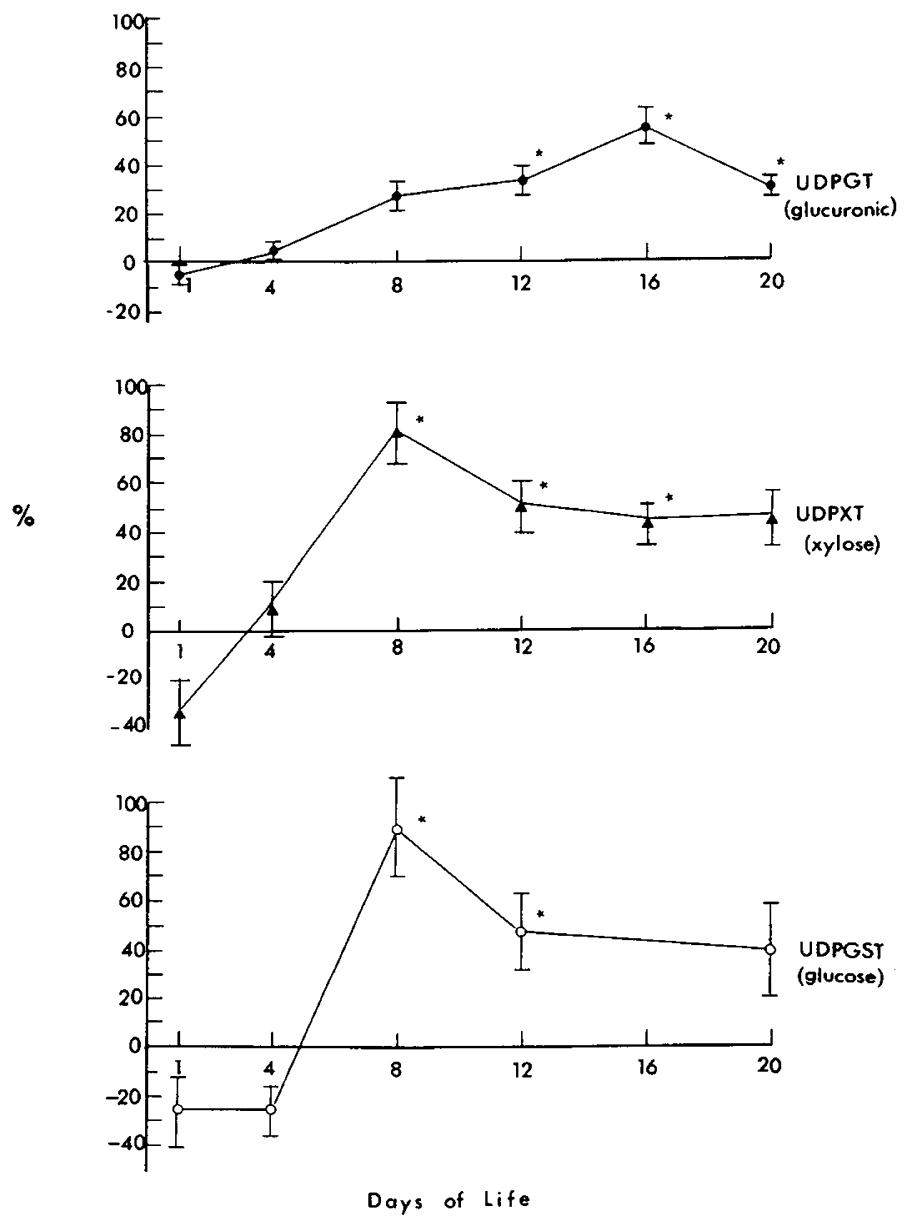

Fig. 3. Percentage of increase in uridine diphosphate glucuronyl transferase (UDPGT), uridine diphosphate xylosyl transferase (UDPXT), and uridine diphosphate glucosyl transferase (UDPGST) activities after phenobarbital treatment in newborn rats as compared with controls of the same age. Results are expressed as the mean \pm SE. *: significant increase in activity. Number of determinations in each group: 1 day, $7 ; 4$ days, $7 ; 8$ days, $6: 12$ days, $8 ; 16$ days, $7 ; 20$ days, 9 . 
Table 1. Liver weights, liver protein concentrations, and total liver protein in adult and newborn rats with and without prior phenobarbital $(P B)$ administration ${ }^{1}$

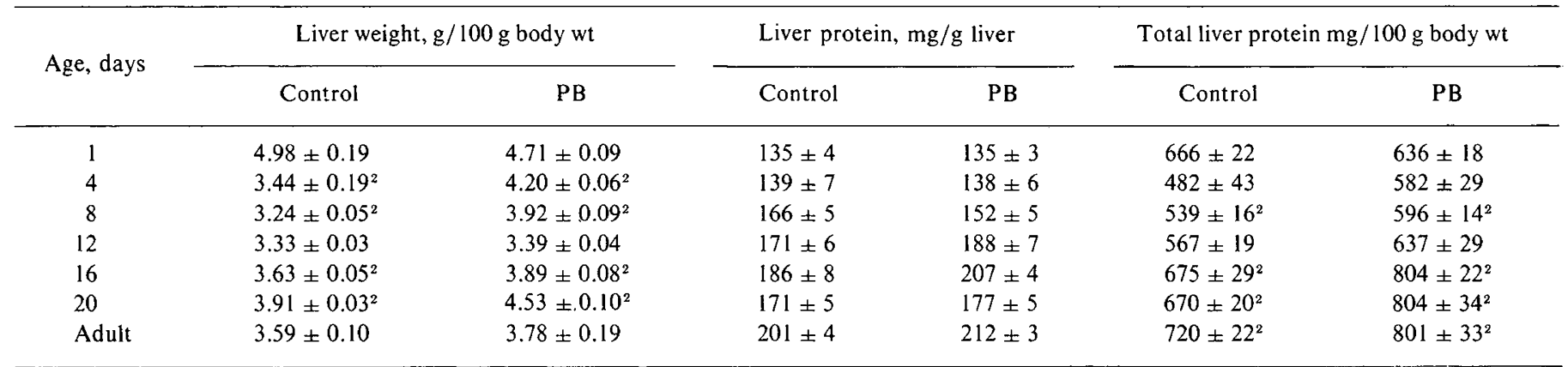

${ }^{1}$ All values are mean \pm SE. Number of determinations in each group (control/phenobarbital): day $1,12 / 7 ;$ day $4,6 / 7 ;$ day $8,6 / 6 ;$ day $12,10 / 8 ;$ day 16, 12/7; day 20,6/9; adult, 19/12.

${ }^{2}$ Significantly different, $P<0.05$.

conjugating enzyme previously studied), relative to the adult, vary widely from one study to the next $(1,3,10,13)$. In general, however, all previous studies demonstrated maximal activity peaks at between 10 and 30 days with peak activities greater than those of adult controls. In the present study maximal total conjugating activity was achieved on days 12 to 16 and exceeded adult mean activity by $30 \%$. Peak activity for UDPGT alone was found on day 12 and declined to adult levels by day 20 .

During the first day of life the conjugation of bilirubin with glucuronic acid accounted for only half of the total capacity. The non-glucuronide conjugates contribute a significant portion of the capacity of the day-old newborn liver to form the water soluble conjugates of bilirubin. As glucuronide conjugation matures to its maximal activity, the non-glucuronide conjugates (glucose and xylose) become relatively less important. All three enzymes decline significantly by the 20 th day. The explanation for this pattern of maturation is lacking.

The significance of the contribution of the non-glucuronide conjugates during the early days of life is supported by the fact that both xylose and glucose conjugation responds earlier than glucuronide conjugation to phenobarbital treatment. Maximal induction, as percentage of enhancement over control, was found on day 8 for both glucose and xylose and on day 16 for glucuronic acid. The greater contribution in the first days of life of xylosyl and glucosyl transferase may, in part, compensate for deficiency of glucuronyl transferase, helping to minimize bilirubin retention.

The failure of 4 days of $\mathrm{PB}$ administration to mother and newborn to increase UDPGT, UDPXT, or UDPGST activity on days 1 and 4 contrasts with the only previous study in rats of bilirubin UDPGT activity after PB treatment, but this study used a different strain of rats and a quite different assay for measurement of UDPGT (10). Increased bilirubin UDPGT activity in response to PB has also been demonstrated in newborn mice (3) and monkeys (8). The failure to induce the enzyme during the first 4 days of life may relate to differences in species, strain, dosage, metabolism of PB, and enzyme assay techniques. Although metabolites of phenobarbital were not determined in the present study, fetal and newborn phenobarbital concentrations in rats were found to be identical with maternal hepatic concentrations (19). In the present assay system, whole homogenates were used. It is possible that similar studies performed with microsomal preparations might reveal significant increases in enzyme activity. If this were the case, it would suggest the presence of inhibitors of enzyme activity in the whole homogenate preparation. Evidence for the presence of inhibitors of glucuronyl transferase is yet to be presented. By the 8th day of life increased bilirubin conjugation was clearly demonstrable in the present study.

The mechanism of control of the observed differences in age-related distribution of the three enzymes is unknown, but several speculations may be considered. (I) Each of the three enzymes may be different and independent, increasing enzyme synthesis in the postpartum period at unrelated rates and responding to drug induction as separate proteins. (2) The low activity of each of the enzymes may be determined, in part or in whole, by the presence of an inhibitor(s), with each enzyme having a different susceptibility to the same or different inhibitor(s). (3) The three enzymes may be structurally related but dependent for their activity on the presence of three separate unidentified cofactors and with each cofactor becoming available at a different time postnatally.

The lipid composition of the liver microsomal membranes has been demonstrated to be an important determinant of the activity of glucuronyl transferase $(9,21)$. The different contributions of the various bilirubin conjugating systems in the newborn and the adult could be due to differences in the phospholipids of the microsomal membranes. Different transferases may require different phospholipids. Changes in hepatic microsomal fatty acid synthesis during development in the rat may account for the earlier maturation of UDPXT and UDPGST than UDPGT.

The type of conjugates formed in vitro are usually found to be present in the bile of the species studied, but the relative distribution of each conjugate in bile need not correlate with enzyme activity (4). Thus, the functional significance of this enzymatic study can only be determined by chromatographic study of bile from newborns, both laboratory animals and humans.

The patterns of enzyme maturation and relative activities in the rat may not represent the human situation. Thus, non-glucuronide conjugation may be of little or no importance in the human newborn. On the other hand, it is possible that in the human, xylose and glucose conjugates may be of even greater importance during the neonatal period than in the rat, particularly after drug stimulation. PB has been demonstrated to be effective in decreasing serum bilirubin concentrations in the human newborn $(16,18)$. The mechanism of this response is not fully understood but could be mediated through an increase in bilirubin conjugates other than glucuronic acid. Further studies are clearly indicated to evaluate the role of different conjugating systems in the human newborn.

\section{SUMMARY}

The development and relative contribution of three different enzymes for hepatic bilirubin conjugation (UDPGT, UDPXT, and UDPGST) were studied in the newborn rat. Total conjugating capacity (summation of three enzyme activities) reached that of adult controls by the fourth day of life. In the first day of life, UDPGT activity accounted for only $50 \%$ of total activity, a significantly smaller proportion of total activity compared with $75 \%$ in the adult. By the eighth day and afterward, the distribution of enzyme activities were the same as in the adult.

Maternal phenobarbital administration did not enhance the 
activity of any of the three enzymes during the first 4 days of life. By the eighth day, however, UDPXT and UDPGST activities increased 80 and $88 \%$ as compared with controls, respectively. UDPGT demonstrated no enhancement on day 8 in response to phenobarbital. By the 12th day, enhancement of UDPGT became significant, reaching maximal increase on day 16 .

\section{REFERENCES AND NOTES}

1. Bakken, A. F.: Effects of unconjugated bilirubin on bilirubin-UDP-glucuronyl transferase activity in liver of newborn rats. Pediat. Res.. 3: 205 (1969).

2. Brown, A. K., and Zuelzer, W. W.: Studies on the neonatal development of the glucuronide conjugating system. J. Clin. Invest., 37: 332 (1957).

3. Catz, C.. and Yaffe, S. J.: Barbiturate enhancement of bilirubin conjugation and excretion in young and adult animals. Pediat. Res., 2: 361 (1968).

4. Cornelius, C. E.. Kelley, K. C., and Himes, J. A.: Heterogeneity of bilirubin conjugates in several species. Cornell Vet., 65: 90 (1975).

5. Fevery, J., Leroy, P., Van De Vijver, M., and Heirwegh, K. P. M.: Structures of bilirubin conjugates synthesized in vitro from bilirubin and uridine diphosphate glucuronic acid, uridine diphosphate glucose or uridine diphosphate xylose by preparation from rat liver. Biochem. J.. 129: 635 (1972).

6. Gartner, L. M., and Arias, I. M.: Hormonal control of hepatic bilirubin transpor and conjugation. Amer. J. Physiol., 222: 1091 (1972).

7. Gartner, L. M., and Lane, D. L.: The physiology of physiologic hyperbilirubinemia of the newborn. Medical Primatology 1972. Proceedings of the Third Conference on Experimental Medicine and Surgery in Primates, Lyon, 1972, Part I. p. 237 (Karger, Basel, 1972).

8. Gartner, L. M. Lee, K. S., Vaisman, S. L.ane, D., and Zarafu, I.: The effect of prenatal and neonatal phenobarbital administration on hepatic bilirubin uptake, conjugation, and excretion in the newborn Macaca mulatta (rhesus) monkey. J. Pediat. (In press.)

9. Graham, A. B., Woodcock, B. G., and Wood, G. C.: The phospholipid-dependence of uridine diphosphate glucuronyl transferase. Biochem. J., 137: 567 (1974).

10. Halac, E., and Sicignano, C.: Re-evaluation of the influence of sex, age, pregnancy and phenobarbital on the activity of UDP-glucuronyl transferase in rat liver. J. Lab. Clin. Med., 73: 677 (1969).
11. Heirwegh, K. P. M., Van Hees, G. P., Leroy, P., Van Roy, F. P., and Jansen, F. $H$.: Heterogeneity of bile pigments conjugates as revealed by chromatography of their ethyl anthranilate azopigments. Biochem. J., 120: 877 (1970).

12. Jansen, P. L. M., and Arias, I. M.: Delipidation and reactivation of UDP glucuronosyl transferase from rat liver. Biochim. Biophys. Acta, 391: 28 (1975).

13. Krasner, J., Juchau, M. R., and Yaffe, S. J.: Postnatal development changes in hepatic bilirubin UDP-glucuronyl transferase. Biol. Neonate, 23: 381 (1973).

14. Lowry, O. H., Rosebrough, N. J., Farr, A. L., and Randall, R. J.: Protein measurement with the Folin phenol reagent J. Biol. Chem., 193: 265 (195I).

15. Runyon, R. P., and Haber. A.: Fundamentals of Behavioral Statistics (AddisonWesley Publishing Co., Reading, Mass.

16. Trolle, D.: Decrease of total serum bilirubin concentration in newborn infants after phenobarbitone treatment. Lancet, ii: 705 (1968).

17. Vaisman, S.: Tesis Universidad de Chile. Hiperbilirrubinemia neonatal y drogas. (Santiago, Chile, January 1972).

18. Vaisman, S. Galecio, R. Erazo, R. and Kunzack, H.: Hiperbilirrubinemia del recien nacido y fenobarbital I. Recien nacido de termino. Rev. Chil. Pediat., 4 245 (1971).

19. Vaisman S. L., Lee, K. S and Gartner L. M. Diminished enhancement of hepatic UDP-glucuronyl transferase (bilirubin) by phenobarbital during pregnancy in the rat. Biol. Neonat. 28: 287 (1976).

20. Wong, K. P.: Bilirubin glucosyl and glucuronyl transferases: A comparative study and the effects of drugs. Biochem. Pharmacol., 2l: 1485 (1972).

21. Zakim, D., Goldenberg, J., and Vessey, D. A.: Influence of membrane lipids on the regulatory properties of UDP-glucuronyl transferase. Europ. J. Biochem. 38: $59(1973)$.

22. This work was supported by grants from National Institute of Child Health and Disease (no. 5R01-HD03783). National Institutes of Health International Fellowship Award (no. 3F05 TW1850-0140151), the Gail I. Zuckerman Foundation for Research in Chronic Liver Diseases of Children, and the Liver Research Center of the Albert Einstein College of Medicine.

23. Dr. S. Vaisman was a recipient of a National Institutes of Health International Fellowship.

24. Dr. L. Gartner is a Career Development Awardee from National Institute of Child Health and Disease.

25. Requests for reprints should be addressed to: L. M. Gartner, M.D., Department of Pediatrics, Albert Einstein College of Medicine, 1300 Morris Park Ave., Bronx, N. Y. 10461 (USA).

26. Accepted for publication June 4, 1976.
Angiotensin II

Bartter's syndrome

plasma renin activity renin-aldosterone axis sodium urinary excretion

\title{
Effect of Sodium Restriction and Angiotensin II Infusion in Bartter's Syndrome
}

\author{
L. SANN, ${ }^{(30)}$ M. DAVID, P. RICHARD, D. FLORET, J. SASSARD, C. A. BIZOLLON, \\ AND R. FRANCOIS
}

Hîpital E. Herriot and Hôpital Debrousse, Lyon, France

Extract

Five patients with Bartter's syndrome were investigated. Sodium restriction $(<10 \mathrm{mEq} /$ day for at least 5 days $)$ showed a renal sodium wastage in only two patients $(I$ and $I I)$ in spite of increased aldosterone secretion rate (from 151-427 to 680-842 $\mu \mathrm{g} / \mathrm{day}$ ). The effect of angiotensin II (A II) $80 \mathrm{ng} / \mathrm{kg} / \mathrm{min}$ for $30-180 \mathrm{~min}$, on plasma renin activity (PRA), plasma aldosterone, and urinary sodium excretion was compared with the effect of a previous infusion of $5 \%$ dextrose given at the same rate, $0.5 \mathrm{ml} / \mathrm{min}$ for $1 \mathrm{hr}$. A II infusion resulted in increased plasma aldosterone levels: from $236-330 \mathrm{pg} / \mathrm{ml}$ to $800-881 \mathrm{pg} / \mathrm{ml}$ in $30 \mathrm{~min}$. This increase was also observed in patient II (from 139 to $600 \mathrm{pg} / \mathrm{ml}$ ). PRA was decreased by $A$ II infusion (from 1,142-2,462 to $121-1,625 \mathrm{ng} / \mathrm{liter} / \mathrm{min}$ ). In patient $I V$, this decrease in PRA was also observed when he was on a salt-restricted diet (from 1,934 to $370 \mathrm{ng} / \mathrm{liter} / \mathrm{min}$ ); but the minimal PRA was still higher $(370 \mathrm{ng} / \mathrm{liter} / \mathrm{min})$ than with a normal diet $(121 \mathrm{ng} / \mathrm{liter} / \mathrm{min})$. In no case could normal PRA level be obtained. A II infusion induced an increase in urinary sodium excretion only in the two patients with renal sodium wastage (from $80-90$ to $265-230 \mu \mathrm{Eq} / \mathrm{min}$ in $30 \mathrm{~min}$ ). Urinary sodium excretion decreased in the other patients from $(37.5-213$ to $4.30-46 \mu \mathrm{Eq} / \mathrm{min})$ and fractional sodium excretion was reduced in patient $V$ (from $0.56 \%$ to $0.45 \%$ at $30 \mathrm{~min}$ and to $0.29 \%$ at $120 \mathrm{~min}$ ). No signifi- 